DOI:10.17951/h.2019.53.2.45-53

\begin{tabular}{lcc}
\hline & A N N A L E S \\
UNIVERSITATIS MARIAE CURIE-SKŁODOWSKA \\
LUBLIN - POLONIA \\
SOL. LIII, 2
\end{tabular}

\author{
PIOTR NIERADKA \\ piotr.nieradka@umcs.pl \\ Maria Curie-Skłodowska University in Lublin, Faculty of Economics, \\ pl. Marii Curie-Skłodowskiej 5, 20-031 Lublin, Poland \\ ORCID ID: https://orcid.org/0000-0002-5791-7448
}

\title{
Using virtual reality technologies in the real estate sector
}

Keywords: virtual reality; real estate; product presentation; visualisation; Poland

JEL: R22; O32; L85

How to quote this paper: Nieradka, P. (2019). Using virtual reality technologies in the real estate sector. Annales Universitatis Mariae Curie-Skłodowska, sectio H - Oeconomia, Vol. 53, No. 2.

\begin{abstract}
Modern virtual reality (VR) technology has a growing impact on further areas of the new digital economy. This is possible due to the declining prices of electronic components, the rapid implementation of new technologies in the market of goods and services and the increasing availability of advanced devices that use the emerging new technology. The purpose of this article is to present the potential of using VR technology in the real estate market. The article identifies solutions that are already successfully operating in the market as well as examples of possibilities for the future use of this technology. The main advantage of using VR in the real estate market is innovation and a multi-sensory form of presenting offers. The presented results of the studies concern the potential of VR technology (the impression that the technology exerts on users, ease of use, functionality of the equipment, the reality of the evoked feelings, possible areas of application). These results are also part of a larger study on VR equipment, which consisted of several stages.
\end{abstract}




\section{Introduction}

The $21^{\text {st }}$ century is the period of the fourth industrial revolution in the history of mankind, a period characterized by the dynamic development of modern technologies based on electronic equipment. One of the branches of this development includes virtual reality (VR) and augmented reality (AR), which are often identified with each other, or their names are used as synonyms. However, they are different concepts and the differences between them are obvious to everyone who has dealt with them.

The term "augmented reality" means a computer-generated system which consolidates the real world with the digital world through the so-called overlaying of digital content (including applications, data, information, video images or photos in two or three dimensional space) on the real world seen through the eyes. Thanks to the application of technology, augmented reality expands the real world that surrounds us, complementing it with digital content (Nieradka, 2017). Virtual reality, however, constitutes a complete environment fully generated by computer hardware that attempts to reproduce a reality within which the user feels immersed (Borsci et al., 2016).

Analysing the above-mentioned concepts, it can be concluded that both technologies (VR and AR) are based on a digital image generated by the computer hardware that is not too far away from the real world that surrounds the user. However, they differ in the number of objects generated along with their mapping in relation to the user of the equipment.

\section{The essence of the real estate market}

There are numerous scientific studies and analyses concerning market mechanisms. In the case of the real estate market, the market object is a property that constitutes a specific commodity. This residential real estate market specificity is due to the following factors: the individual nature of the transaction, the heterogeneous nature of the market, price and cost variability, and the demand for and supply of a given commodity. Nevertheless, researching the real estate market is particularly important for achieving greater transparency.

Thus, the nature of real estate can be highly diverse, which, as a consequence, means that housing price analysis is complicated and composed of many factors. Due to the significant heterogeneity of real estate, it seems reasonable to perceive the price element of real estate as a set of qualities of the selected features of the product (Rosen, 1972). In addition, it should be noted that the heterogeneity of real estate refers to physical, economic and social differences.

The Internet has become an excellent intermediary in the consumer-to-consumer relationship, being both the fastest and the most recent channel. Currently, thanks to new technological possibilities, the Internet has become an even more perfect tool and a weapon for companies participating in the market war for the attention of customers, 
in the name of their trust and commitment to the presented market offers. The leading idea of constant marketing (proprietary offer) and the development of the ways in which this offer can be presented is aimed at increasing competitiveness. The concept of outstanding sellers and strategists, as outlined by Al Ries and Jack Trout, is very appropriate here. In their book entitled Positioning: The Battle for Your Mind, the authors instil the idea that you must distinguish yourself on the market or die (Ries $\&$ Trout, 2001). The slogan has become not only a mantra of marketing but of the entire free market economy. Your offer for the customer must exceed the offer of the competition, creating some added value, which will draw the customer's attention and make them choose your offer.

When discussing creating added value in the real estate industry, we should also recall the words of the world-renowned marketing professor Gerald Zaltman from Harvard Business School. In his research, he found that customers think with images. This means that everything that stimulates our senses is transformed into visual, verbal or other forms of images (Zaltman, 2003). The well-known saying that "an image is worth more than a thousand words" very accurately reflects the scientific correlation confirmed by Zaltman.

\section{Immersion as the way of presentation}

There is a growing discrepancy between the wealth of digital data and information and the physical world. Although the reality that surrounds us is three-dimensional, a significant amount of data and information used today for management and presentation still occurs on two-dimensional pages of documents presented on computer screens. The resulting gap between the real world and the digital world can be significantly offset by the correct use of virtual technology and augmented reality.

The experience of VR or AR is not only based on an image, but also sound or sensations and, above all, a different way of control and interaction with software, significantly different from the one currently used by the majority of the public. Although there is still a long way to go to the advanced level of interaction shown in films such as Minority Report, Tron: Legacy or Player One, the first steps in this direction have undeniably already been taken. The opportunity to provide new users with new deep experiences and a deep level of immersion which they have not encountered before is a fact. This is undeniably an area where we can express our ideas in a new creative and unique way.

\section{Using VR technology in the real estate segment}

The evidence suggests that VR technology is conquering the market slower than initially expected, but taking this path should pay off in the future. The VR solution will allow real estate agencies to achieve a market advantage over competition, 
thanks to the earlier adaptation of the new promising technology, working out the added value for the brand and the enterprise. VR and AR technology fits very well into the real estate industry, allowing for activities including:

- Virtual tours of property - allowing free physical or virtual movement, using motion controllers, throughout the entire area of the presented property.

- 360 degree visualisations - the ability to teleport through available location points without having to move from the current site of the visualisation.

- Visualisation of the room furniture - the possibility of better visualisation of prepared finishing designs, allowing for a better presentation of design concepts without the need to invest in furniture and exhibition space.

Currently, there are several solutions on the market that are used to present property, including:

- VR High-End Experiences - using advanced VR solutions with the complete set of equipment (headset, headphones, controllers) to provide the customers with the best possible VR experience. This solution allows you to freely explore and stimulate the customer's emotions by presenting, for example, changing seasons behind the window or on the balcony, creating a vision by providing customers with exceptional experiences.

- VR Walkthroughs - based on mobile devices such as smartphones, where the headset and controllers are omitted, leaving only a headset. The 3D experience is still achieved, but in this case the designer can lead many viewers through the previously prepared interactive show route. This solution is better suited for large displays in sales offices, conference rooms or when organizing other events.

- 3D Touchscreen Interfaces - based on ordinary computer hardware, where you can navigate between prepared points in the property area using the navigation menu on the computer screen. Within the points, a professional 360 degree view is available that allows for a better presentation of the property than photos posted on Internet portals.

In the VR field, there are an increasing number of companies offering this type of programming as well as organizations from the construction sector or brokers in real estate sales, for example: SKANSKA (Stryfon-Bojarska \& Kemmer, 2017), ATLAS BAY VR (2018), IRISVR (2018), ENSCAPE (2018), TrueScale (2018), IKEA VR Experience (2018) or Home Planner for IKEA (2018).

\section{Study method}

Due to the significant development of the field of extended reality paired with slow integration into new sectors, and due to new emerging issues that require investigation, further own research has been carried out using virtual reality equipment. Eighty seven people participated in extensive study on the equipment. The test lasted between 110 and 193 minutes and was dependent on the skill level and ability of individuals to use the equipment. The test consisted of the following stages: 
Stage I. An online questionnaire with questions about the respondent's previous experience with virtual reality devices.

Stage II. A test using Cardboard.

Stage III. Assessment of Cardboard.

Stage IV. A test using VR Box.

Stage V. Assessment of VR Box.

Stage VI. A test using HTC VIVE.

Stage VII. Assessment of HTC VIVE and the general opinion about all the tested VR devices.

The test involved the practical use of equipment together with passing general guidelines on the use by the user. An anonymous survey was then carried out for the collection of unique experiences from the respondents by means of CAWI (computer-assisted web interview). Due to security reasons and data protection issues, the electronic questionnaire was stored on the department website (http://ankiety.ekonomia. umcs.lublin.pl).

Six records $(6.9 \%)$ were deleted from the dataset due to blank or partially filled boxes in the questionnaire. The final size of the study sample is 81 respondents. The characteristics of the test sample are as follows: $51.85 \%$ of respondents are men and $48.15 \%$ of respondents are women. In the group of respondents there were $40.74 \%$ of people aged 16-24, 38.27\% between 25 and 34 years, $12.35 \%$ between 35 and 44 years, $6.17 \%$ between 45 and 54 years and two people over 55 years.

Most of the respondents declared a city with 200,000-499,999 inhabitants (55.56\%) as their place of residence, followed by a village (22.99\%), a city below 50,000 residents $(11.11 \%)$ and a city between 500,000 and $1,000,000$ inhabitants $(6.17 \%)$, and the smallest number of respondents lived in a city with a population exceeding $1,000,000$ inhabitants (1.23\%). Respondents declared the following economic activity: employment contract work (46.91\%), university student (38.27\%), contract work $(6.17 \%)$, own business (3.70\%), school student (2.47\%), unemployed (1.23\%) and retirement/ pension $(1.23 \%)$.

Participants of the study were also asked to provide their completed level of education, whereby the majority (43.21\%) chose second degree studies, followed by secondary education $(32.10 \%)$, third degree studies $(11.11 \%)$, first degree studies $(6.17 \%)$, elementary $(3.70 \%)$, post-secondary $(2.47 \%)$ and vocational $(1.23 \%)$.

The collected unique dataset was analysed and processed by the author, and some of the collected results from the broad base are presented in the next part of the article.

\section{Results}

Step VI of the study involved opinions and feelings of respondents on the tested VR hardware and evaluation of the use cases and development of this technology in the modern world. The participants were asked to respond to certain statements 
related to the HTC VIVE device. A five-point Likert scale was used with values ranging from 1 (very poor) to 5 (very good) and the answers are presented in Table 1 .

The respondents showed a positive attitude to the device subject to testing. As many as $95.06 \%$ of the respondents said that by using HTC VIVE they felt immersed, with only $4.94 \%$ giving "no" answers. There was also a question about the type and strength of experiences during the use of the advanced virtual reality device; the results are shown in Figure 1. The experiences were very positive with the exception of smell sensations, which ranked neutral, despite the lack of an aroma-generating device during the research.

Table 1. Responders' attitude towards the presented statements

\begin{tabular}{|c|c|c|c|c|c|}
\hline & 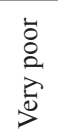 & ¿े & 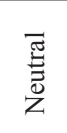 & $\begin{array}{l}\overrightarrow{8} \\
\dot{8}\end{array}$ & $\begin{array}{l}\overrightarrow{8} \\
8 \\
00 \\
2 \\
2 \\
>0\end{array}$ \\
\hline The first impression after direct contact with the device & $0 \%$ & $0 \%$ & $4 \%$ & $21 \%$ & $75 \%$ \\
\hline How do you evaluate the ease of use? & $0 \%$ & $0 \%$ & $7 \%$ & $47 \%$ & $46 \%$ \\
\hline How do you evaluate the intuitiveness of use? & $0 \%$ & $0 \%$ & $6 \%$ & $44 \%$ & $49 \%$ \\
\hline The comfort of using the virtual reality headset & $0 \%$ & $2 \%$ & $20 \%$ & $44 \%$ & $33 \%$ \\
\hline The handiness of using the virtual reality headset & $0 \%$ & $4 \%$ & $20 \%$ & $47 \%$ & $30 \%$ \\
\hline Controller weight & $0 \%$ & $4 \%$ & $7 \%$ & $41 \%$ & $48 \%$ \\
\hline Controller size & $0 \%$ & $4 \%$ & $7 \%$ & $41 \%$ & $48 \%$ \\
\hline Controller convenience & $0 \%$ & $1 \%$ & $9 \%$ & $42 \%$ & $48 \%$ \\
\hline Controller handiness & $0 \%$ & $1 \%$ & $6 \%$ & $47 \%$ & $46 \%$ \\
\hline Device wiring & $4 \%$ & $27 \%$ & $33 \%$ & $25 \%$ & $11 \%$ \\
\hline Freedom of movement & $1 \%$ & $10 \%$ & $22 \%$ & $40 \%$ & $27 \%$ \\
\hline HTC VIVE ease of use & $0 \%$ & $0 \%$ & $4 \%$ & $65 \%$ & $31 \%$ \\
\hline The level of device intuitiveness & $0 \%$ & $0 \%$ & $9 \%$ & $22 \%$ & $69 \%$ \\
\hline Colour & $0 \%$ & $1 \%$ & $1 \%$ & $46 \%$ & $52 \%$ \\
\hline Picture clarity & $0 \%$ & $1 \%$ & $11 \%$ & $37 \%$ & $51 \%$ \\
\hline
\end{tabular}

Source: Author's own study.

\section{Sense of Immersion}

Visual experience

Audio experience

Olfactory sensations

Tactile sensation

Sense of interaction

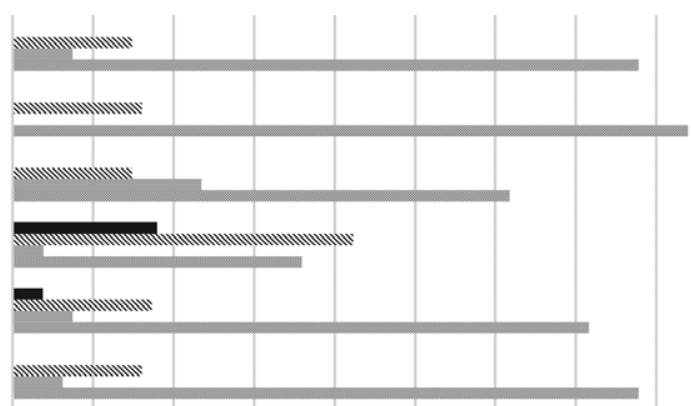

None

Weakest

Medium

- Strongest

\section{$\begin{array}{lllllllllll}0 \% & 10 \% & 20 \% & 30 \% & 40 \% & 50 \% & 60 \% & 70 \% & 80 \% & 90 \%\end{array}$}

Figure 1. Types and strength of various sensations associated with the use of HTC VIVE Source: Author's own study. 
The subsequent questions concerned: the potential, sensations, image and the level of reality created by VR (see Table 2), which were also assessed very positively. The answers demonstrate that proper software designed for the dedicated equipment and using a high level of immersion would enable, to a large extent, the advantages of real estate to be shown very realistically in order to enhance the interest in the offer.

In the question "In what sectors of the economy do you think this solution can be used?" the respondents also pointed to real estate trading as a possible area for the use of virtual reality technology. The potential for using VR in the real estate sector is also confirmed by Figure 2, according to which the use of this technology would encourage the surveyed people to purchase the presented goods or real estate.

Table 2. The responders' opinion on VR equipment

\begin{tabular}{|c|c|c|c|c|c|}
\hline & 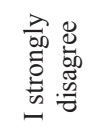 & 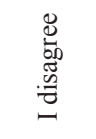 & 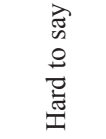 & 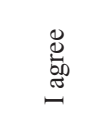 & 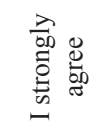 \\
\hline $\begin{array}{l}\text { Virtual reality technology has a great potential to } \\
\text { create experiences. }\end{array}$ & $0.00 \%$ & $0.00 \%$ & $3.70 \%$ & $40.74 \%$ & $55.56 \%$ \\
\hline $\begin{array}{l}\text { Virtual reality generates a highly realistic version of } \\
\text { reality/the world. }\end{array}$ & $0.00 \%$ & $2.47 \%$ & $11.11 \%$ & $54.32 \%$ & $32.10 \%$ \\
\hline Sensations generated by virtual reality are very real. & $1.23 \%$ & $4.94 \%$ & $12.35 \%$ & $44.44 \%$ & $37.04 \%$ \\
\hline $\begin{array}{l}\text { Pictures generated by VR devices are highly } \\
\text { realistic. }\end{array}$ & $0.00 \%$ & $3.70 \%$ & $12.35 \%$ & $59.26 \%$ & $24.69 \%$ \\
\hline
\end{tabular}

Source: Author's own study.

Would using virtual reality technology to view products/goods/property encourage you to make a purchase?

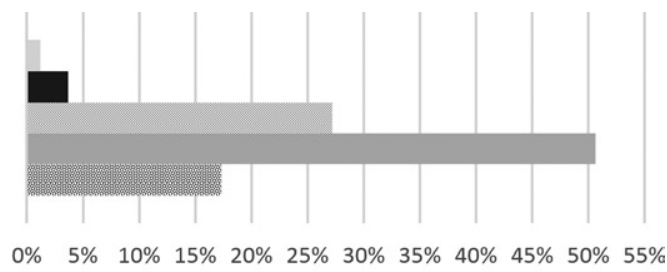

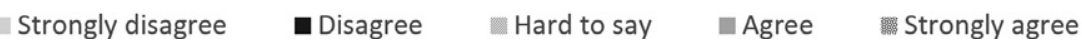

Figure 2. Using VR in the sales of goods and real estate

Source: Author's own study.

\section{Conclusions}

The results of the studies conducted confirm that using virtual reality equipment in the real estate business is a good idea. The non-standard form of presentation of an offer using VR acts as an added factor that encourages customers to purchase 
real estate. Thus, VR can become an element that increases the competitiveness of an organisation on the market by creating added value for a potential customer. This is confirmed by examples of applications or software already present on the market that are being successfully used. It should be noted, however, that such implementations are still niche in nature, while most market players operate on the basis of traditional methods.

VR solutions have the potential to better meet the pressure on the attribute of location, i.e. a very important factor for the customer. Such solutions would allow certain real estate to be visited in an almost physical way using immersion effects, without the need to physically move between sites. When this technology is used in combination with dedicated equipment, enabling many locations to be presented at the same time by developers or brokers from all over the world without having to leave your home, office or real estate agency, it will increase the competitiveness of the organisation on the market thanks to the added value created in this way. An additional advantage is the possibility to strengthen the positive experiences (see Figure 1) of potential customers through a virtual three-dimensional presentation of your market offer.

There are some limitations regarding the ability of this study to be generalised, as it has been carried out on a local scale. Obtaining the full picture of the phenomenon of using virtual reality technology in the field of real estate requires the conduction of more cross-sectional research on a national scale. However, the technology of virtual and augmented reality is still at the initial stage of development and we still have to wait several more years for VR headsets to replace TVs or computer monitors, and for VR/AR goggles to replace phones and tablets. This will certainly happen much faster than we expect, which is why companies should pay more attention to virtual technology and begin to consider its application in their structures.

\section{References}

ATLAS BAY VR. (2018). Retrieved from https://www.atlasbayvr.com [access: 8.09.2018].

Borsci, S. et al. (2016). Effectiveness of a multidevice 3D virtual environment application to train car service maintenance procedures. Virtual Reality, 20(1), pp. 41-55. DOI: http://dx.doi.org/10.1007/ s10055-015-0281-5.

ENSCAPE. (2018). Retrieved from https://www.atlasbayvr.com [access: 7.09.2018].

Home Planner for IKEA. (2018). Retrieved from https://play.google.com/store/apps/details?id=com.planner5d.swedishhomedesign\&hl=pl [access: 7.09.2018].

IKEA VR Experience. (2018). Retrieved from https://www.ikea.com/ms/en_US/this-is-ikea/ikea-highlights/ Virtual-reality/index.html [access: 8.09.2018].

IRISVR. (2018). Retrieved from https://irisvr.com [access: 7.09.2018].

Nieradka, P. (2017). VR - rozpoznawalność sprzętu w świetle wyników badań empirycznych. Problemy Zarzadzania, 4(71), pp. 71-82. DOI: 10.7172/1644-9584.71.5.

Ries, A., \& Trout, J. (2001). Positioning: The Battle for Your Mind. New York: McGraw-Hill. 
Pobrane z czasopisma Annales H - Oeconomia http://oeconomia.annales.umcs.pl

Data: 26/04/2023 11:22:16

Rosen, S. (1972). Hedonic prices and implicit markets: Product differentiation in pure competition. The Journal of Political Economy, 82(1), pp. 34-55.

Stryfon-Bojarska, A., \& Kemmer, W. (2017). Potencjat do zastosowania technologii VR $i$ AR $w$ branży budowlanej-SKANSKA, European AR/VR Congress, held on 23-24 November at Copernicus Conference Centre in Warsaw.

TrueScale. (2018). Retrieved from https://immersion.pl/project/truescale/ [access: 8.09.2018].

Zaltman, G. (2003). How Customers Think: Essential Insights into the Mind of the Market. Boston: Harvard Business School Press. 